\title{
A cohort study of antihypertensive treatments and risk of renal cell
}

\section{cancer}

\author{
JP Fryzek ${ }^{* 1,2}$, AH Poulsen ${ }^{3}$, SP Johnsen ${ }^{4,5}$, JK McLaughlin ${ }^{1,2}$, HT Sørensen ${ }^{4}$ and S Friis ${ }^{3}$ \\ 'International Epidemiology Institute, Rockville, MD, USA; ${ }^{2}$ Department of Medicine, Vanderbilt University Medical Center, Vanderbilt-Ingram \\ Comprehensive Cancer Center, Nashville, TN, USA; ${ }^{3}$ Institute of Cancer Epidemiology, Danish Cancer Society, Copenhagen, Denmark; ${ }^{4}$ Department of \\ Clinical Epidemiology, Aarhus University Hospital, Aarhus, Denmark; ${ }^{5}$ Department of Cardiology, Aaborg Hospital, Aalborg, Denmark
}

We studied 335682 county residents, of whom I 13298 had been prescribed antihypertensive treatment (AHT), in the period 1989-2002 in North Jutland County, Denmark to examine the relation between different AHTs and the risk of renal cell carcinoma (RCC). An internal comparison was performed among the different classes of AHT users with users of beta blockers as the reference, in order to address potential confounding and bias. The average follow-up was 10 years (range $0-13$ ). Use of any AHT was associated with RCC (relative rate $(\mathrm{RR})=1.6,95 \%$ confidence interval $(\mathrm{Cl})$ 1.3-1.9) compared with nonusers in the general population. Specific classes of AHTs were nonsignificantly associated with RCC, but compared with users of beta blockers, the numbers observed were close to expectation. Analyses by duration of follow-up and number of prescriptions revealed no clear trends for any antihypertensive agent and after 5-years of follow-up, the RRs for all classes of AHT decreased. The elevated RRs for RCC among users of AHTs compared with the general population are unlikely to be causal, but rather reflect confounding due to failure to control for pre-existing hypertension, and protopathic bias, due to the presence of hypertension as an early sign of kidney disease.

British Journal of Cancer (2005) 92, I302- |306. doi: I0.1038/sj.bjc.6602490 www.bjcancer.com (c) 2005 Cancer Research UK

Keywords: antihypertensives; diuretics; renal cell cancer incidence; risk; epidemiology; cohort study

Hypertension is estimated to contribute to one in eight deaths worldwide (WHO, 2002) and up to $60 \%$ of affected individuals in the US are on antihypertensive treatment (AHT) (Chobanian et al, 2003). Concerns have been raised that certain AHT may increase the risk of renal cell carcinoma (RCC) whether by being directly carcinogenic, by eliciting or accelerating other carcinogens, or by impairing defence mechanisms (Yu et al, 1986; McLaughlin et al, 1995; Grossman et al, 2001).

Past studies have suggested an association between diuretics and RCC, but other AHTs were not studied as extensively. Though we have reported on use of calcium channel blockers and ACE inhibitors in relation to cancer in general in North Jutland County, Denmark, we did not look in any detail at RCC risk in relation to the wide variety of specific AHTs (Olsen et al, 1997; Sorensen et al, 2000; Friis et al, 2001); these earlier studies had relatively short follow-up periods, ending in 1993, 1995 and 1996, respectively. The current study updates the follow-up period through 2002 and examines the relation between the all five major classes of AHTs (Capella, 1993), that is, diuretics, beta blockers, calcium antagonists, angiotensin converting enzymes (ACE) inhibitors and

*Correspondence: Dr JP Fryzek, International Epidemiology Institute, I 455 Research Blvd, Suite 550, Rockville, MD 20850, USA

E-mail: fryzek@aol.com

Received 20 October 2004; revised 12 January 2005; accepted 2 February 2005 angiotensin II antagonists, as well as specific classes of diuretics, in relation to RCC.

\section{MATERIALS AND METHODS}

\section{Study population}

The study was conducted among 335682 residents of North Jutland County, Denmark, with no prior diagnosis of any type of cancer, between 30 and 85 years old, and resident in the county on 1 January 1989. Age was restricted to those between 30 and 85 years old because of the limited number of people outside these ages who were first time users of AHT. Of these, 113298 had been prescribed an AHT between the years 1989 and 2002. These data sources have been described in previous studies in this population (Olsen et al, 1997; Sorensen et al, 2000; Friis et al, 2001)

\section{Exposure group}

Prescriptions of AHT medications were ascertained from the Pharmacoepidemiological Prescription Database for individuals in the study population between the years 1989 and 2002. Along with type of drug prescribed according to the Anatomical Therapeutical Chemical (ATC) classification system (Capella, 1993), date of dispensing at the pharmacy and the patient's civil registry number were abstracted from this database. In an attempt to address the problem of noncompliance, we required two or more AHT 
prescriptions recorded in the prescription database during the study period for a person to be classified as exposed. To ensure correct identification of exposure status for those who might have started AHT therapy prior to 1989, 1989 data were used only to assess exposure status, and follow-up was initiated in 1990.

AHT medications were recorded in the pharmacy database by their ATC code, managed and developed by the World Health Organization (WHO, 2004). In this classification system, the drugs are divided into different groups according to the organ or system on which they act and their chemical, pharmacological and therapeutic properties. For this study, we identified all prescriptions filled for AHT medications, including diuretics (ATC group $=\mathrm{C} 03$ ), beta blockers (ATC group $=\mathrm{C} 07)$, calcium channel blockers (ATC group $=$ C02D, C08C, C08D (minus C08DA51)), $\mathrm{ACE}$ inhibitors (ATC group $=\mathrm{C} 02 \mathrm{E}, \mathrm{C} 02 \mathrm{~L}, \mathrm{C} 09 \mathrm{~A}, \mathrm{C} 09 \mathrm{BA}$ ) and angiotensin II antagonists (ATC group $=$ C09C, C09D). In addition, specific types of diuretics were examined. These included thiazides $($ ATC group $=\mathrm{C} 03 \mathrm{~A})$; sulphonamides, mercurial diuretics, xanthine derivatives and other low-ceiling diuretics except thiazides (ATC group $=\mathrm{C} 03 \mathrm{~B}$ ); loop (or high-ceiling diuretics) (ATC group $=$ C03C); potassium-sparing agents (ATC group =C03D); and diuretics and potassium-sparing agents in combination (ATC group $=\mathrm{C} 03 \mathrm{E})$.

\section{Renal cell cancer (RCC)}

Cases of RCC had either an ICD7 code of 180.0 (kidney cancer, not otherwise specified) or 180.3 (renal cell cancer). 'Kidney cancers, not otherwise specified', were regarded as situated in the renal parenchyma as a previous validation study indicated that most of these tumours are RCC (Mellemgaard et al, 1993). We excluded cancers of the renal pelvis and ureter $(\mathrm{ICD} 7=180.1,180.2)$ as their aetiology resembles that of bladder cancer (McLaughlin and Lipworth, 2000).

\section{Follow-up}

Follow-up began on the date of the second prescription for AHT medication or 1 January 1990, whichever was later. Follow-up ended at diagnosis of RCC, age 85, death, emigration from the county, or 31 December 2002, whichever was earliest. The persontime of the study subjects was distributed according to use of AHT medications in exposed time ( $\geqslant 2$ prescriptions for AHT) (AHT users) and unexposed time (one or no prescriptions for any AHT) (nonusers).

\section{Statistical analysis}

Simple descriptive statistics, including frequencies, percentages and means, were calculated to describe the study cohort. Loglinear Poisson regression analysis with the logarithm of personyears at risk as an offset variable was used to estimate the rate ratios associated with use of each type of AHT medication. All models were adjusted for calendar period (1990-1994 or 1995$2002)$, gender and age group $(30-49,50-59,60-69$ or $70-85)$. Subjects could change between categories of covariates and specific types of AHT over time, except for the analyses of 'exclusive users' where subjects did not change between categories of specific types of AHT use. In order to control for potential unmeasured confounding or bias in risk estimates for users of AHT medication based on comparisons with the general population, we also performed a direct comparison between users of a specific AHT and beta blockers. Beta-blockers' pharmacodynamic 'target organs' are outside the kidney (namely heart and vessels). These direct comparisons were restricted to 'exclusive users' of the various AHT medications, including the reference category of beta blockers. Beta blockers were chosen as the reference group because there is no consistent evidence that use of these compounds is associated with increased risk of cancer (Grossman et al, 2001). Since many of these drugs could be used in combination, we also performed analyses for 'exclusive users' of specific AHT medications.

Further stratified analyses on the whole study population comparing AHT users and the general population for duration of follow-up (1, 1-4 and 5 or more years) and number of prescriptions $(2-4,5-9,10+$ prescriptions) were also performed. Within each categorical level all variables were treated as time independent. The statistical analysis was performed in SAS 8.02.

\section{RESULTS}

For the 335682 people in the study population, the average followup was 10 years (range $=0-13$ years). The 113298 people prescribed two or more AHT prescriptions (exposed cohort) accrued a total of 706428 person-years of follow-up, yielding an average follow-up of 6 years (range $=0-13$ years). Other characteristics of AHT users are shown in Table 1. More women $(58 \%)$ than men $(42 \%)$ were prescribed AHT and, as expected, most of the prescriptions were for people over age $50(77 \%)$ with

Table I Characteristics of users of antihypertensive medications, North Jutland, Denmark, 1989-2002

\begin{tabular}{lcc}
\hline & \multicolumn{2}{c}{$\begin{array}{c}\text { Antihypertensive medication } \\
\text { users }\end{array}$} \\
\cline { 2 - 3 } Characteristic & Number & Percent \\
\hline Total & 113298 & $(100)$ \\
Men & 47373 & $(42)$ \\
Women & 65925 & $(58)$ \\
Age at entry & & \\
$<50$ years & & $(23)$ \\
$50-69$ years & 25900 & $(44)$ \\
$\geqslant 70$ years & 49768 & $(33)$
\end{tabular}

Mean age at entry (range) $)^{b} \quad 62$

Year of entry

$1990-1992 \quad 53139$

$1993-1995 \quad 20786$

$1996-1998$

$1999-2002 \quad 22655$

$(47)$

$(18)$

Number of prescriptions for any antihypertensive medication

$2-5 \quad 21294$

$6-10 \quad 13688$

$11-20$

13688

$\geqslant 20$

59495

Type of antihypertensive medication ${ }^{c}$

Any antihypertensive

113298

ACE inhibitor

29486

Angiotensin II antagonist

Beta blocker

13755

42866

Calcium antagonist

Diuretic

34816

83060

Low-ceiling diuretics, thiazides

45714

Sulphonamides and other low-ceiling

4976

diuretics

Loop (high-ceiling) diuretics

Potassium-sparing agents

Diuretics and potassium-sparing

7894

15582

(34)

agents in combination

${ }^{a}$ Two or more prescriptions for antihypertensive medications. ${ }^{b}$ Date of second prescription. "Since cohort members may use more than one antihypertensive medication, the total number exceeds the total number of people in the cohort. 
the average age of entry into the AHT user cohort (the date of the second AHT prescription) of 62 years (range $=30-85$ years). More than half of the cohort (53\%) had received 20 or more prescriptions for AHT. Diuretics were the most common type of AHT medication prescribed (25\%), most of which were thiazides. Beta blockers and calcium antagonist were prescribed for at least $10 \%$ of the population of AHT users, while fewer prescriptions were filled for ACE inhibitors and angiotensin II antagonists.

After controlling for age, gender and calendar period, users of any type of AHT were 1.6 times $(95 \% \mathrm{CI}=1.3-1.9)$ more likely to have RCC compared with individuals in the general population who did not use AHTs (Table 2). Use of ACE inhibitors (relative rate $(\mathrm{RR})=1.9,95 \% \mathrm{CI}=1.4-2.5)$, beta blockers $(\mathrm{RR}=1.7,95 \%$ $\mathrm{CI}=1.3-2.2)$, calcium antagonist $(\mathrm{RR}=1.4,95 \% \mathrm{CI}=1.0-1.8)$ and diuretics $(\mathrm{RR}=1.6,95 \% \mathrm{CI}=1.2-2.0)$ were all significantly associated with RCC. Furthermore, the risk for RCC among each specific class of diuretics was elevated, with a significant association for loop diuretics $(\mathrm{RR}=2.0,95 \% \mathrm{CI}=1.5-2.7)$, and potassium-sparing agents $(\mathrm{RR}=2.2,95 \% \mathrm{CI}=1.3-3.8)$.

Next, we examined the relation between exclusive use of a specific class of AHT and RCC risk. Most of the relative risks were attenuated but slight to moderately elevated risks were still present. However, there were no significant differences in RCC risk among different classes of drugs when exclusive users of specific AHT medications were compared with beta blocker users, with risks of $1.2(95 \% \mathrm{CI}=0.4-3.3)$ for ACE inhibitors, $1.0(95 \%$ $\mathrm{CI}=0.1-7.5)$ for angiotensin II antagonist, $0.9(95 \% \mathrm{CI}=0.4-1.9)$ for calcium antagonist, and $0.9(95 \% \mathrm{CI}=0.5-1.6)$ for diuretics.

Table 3 presents the association between the various classes of AHT and RCC by duration of follow-up using the general population as the comparison group. Overall, the relation between

Table 2 Relative rates (RR) and 95\% confidence intervals (Cl) for the relation between antihypertensive medication use and renal cell cancer (RCC) for individuals who ever used a specific class of antihypertensive medication and for those who exclusively used a specific class of antihypertensive medication compared to the general population or to people who use beta blockers in North Jutland County, 1989-2002

\begin{tabular}{|c|c|c|c|c|c|c|c|c|c|c|}
\hline & \multicolumn{4}{|c|}{ Ever used antihypertensive medication } & \multicolumn{6}{|c|}{ Exclusive use of specific class of antihypertensive medication } \\
\hline & $\begin{array}{l}\mathrm{RCC} \\
\text { cases }\end{array}$ & \multicolumn{3}{|c|}{ General population } & $\begin{array}{l}\mathrm{RCC} \\
\text { cases }\end{array}$ & \multicolumn{3}{|c|}{ General population } & \multicolumn{2}{|c|}{ Beta blockers } \\
\hline Any antihypertensive & 191 & 706428 & 1.6 & $(1.3-1.9)$ & & & & & & \\
\hline ACE inhibitor & 52 & 147096 & 1.9 & $(1.4-2.5)$ & 5 & 18545 & 1.8 & $(0.8-4.5)$ & 1.2 & $(0.4-3.3)$ \\
\hline Calcium antagonist & 59 & 195715 & 1.4 & $(1.0-1.8)$ & 9 & 34915 & 1.3 & $(0.6-2.5)$ & 0.9 & $(0.4-1.9)$ \\
\hline Diuretic & 138 & 489470 & 1.6 & $(1.2-2.0)$ & 55 & 236455 & 1.4 & $(1.0-1.9)$ & 0.9 & $(0.5-1.6)$ \\
\hline Thiazides & 62 & 248890 & 1.3 & $(0.9-1.7)$ & 14 & 77421 & 1.0 & $(0.6-1.7)$ & 0.7 & $(0.3-1.5)$ \\
\hline $\begin{array}{l}\text { Sulphonamides and other } \\
\text { low-ceiling diuretics }\end{array}$ & 9 & 35407 & 1.4 & $(0.7-2.7)$ & 3 & 11482 & 1.6 & $(0.5-5.0)$ & I.I & $(0.3-3.7)$ \\
\hline Loop (high-ceiling) diuretics & 70 & 168311 & 2.0 & $(1.5-2.7)$ & 13 & 41785 & 1.6 & $(0.9-2.8)$ & 1.1 & $(0.5-2.4)$ \\
\hline Potassium-sparing agents & 15 & 30550 & 2.2 & $(1.3-3.8)$ & I & 1164 & 5.0 & $(0.7-36.0)$ & 3.3 & $(0.4-25.1)$ \\
\hline
\end{tabular}

${ }^{a}$ Adjusted for age, gender and calendar period.

Table 3 Relative rates (RR) and 95\% confidence intervals (Cl) for the relation between antihypertensive medication use and renal cell cancer (RCC) by years of follow-up in North Jutland County, 1989-2002

\begin{tabular}{|c|c|c|c|c|c|c|c|c|c|c|c|c|}
\hline \multirow[b]{2}{*}{ Years of follow-up } & \multicolumn{4}{|c|}{$<\mathbf{I}$ year } & \multicolumn{4}{|c|}{ I -4 years } & \multicolumn{4}{|c|}{$5+$ years } \\
\hline & $\begin{array}{l}\text { Number } \\
\text { RCC }\end{array}$ & $\begin{array}{l}\text { Person- } \\
\text { years }\end{array}$ & $\mathbf{R R}^{\mathbf{a}}$ & $95 \% \mathrm{Cl}$ & $\begin{array}{l}\text { Number } \\
\text { RCC }\end{array}$ & $\begin{array}{l}\text { Person- } \\
\text { years }\end{array}$ & $\mathbf{R R}^{\mathbf{a}}$ & $95 \% \mathrm{Cl}$ & $\begin{array}{l}\text { Number } \\
\text { RCC }\end{array}$ & $\begin{array}{l}\text { Person- } \\
\text { years }\end{array}$ & $\mathbf{R R}^{\mathbf{a}}$ & $95 \% \mathrm{Cl}$ \\
\hline Any hypertensive & 33 & 95484 & 2.0 & $(1.4-2.9)$ & 89 & 323680 & 1.6 & $(1.2-2.0)$ & 69 & 287264 & 1.4 & $(1.0-1.8)$ \\
\hline ACE inhibitor & 12 & 26154 & 2.3 & $(1.3-4.2)$ & 30 & 71859 & 2.2 & $(1.5-3.2)$ & 10 & 49084 & 1.1 & $(0.6-2.1)$ \\
\hline Angiotensin II antagonist & 4 & 12072 & 1.9 & $(0.7-5.0)$ & 5 & 27022 & 1.0 & $(0.4-2.5)$ & 0 & 4362 & 0.0 & - \\
\hline Beta blocker & 14 & 37211 & 2.2 & $(1.3-3.8)$ & 34 & 114335 & 1.7 & $(1.2-2.5)$ & 24 & 94425 & 1.4 & $(0.9-2.1)$ \\
\hline Calcium antagonist & 9 & 30749 & 1.4 & $(0.7-2.7)$ & 31 & 96677 & 1.5 & $(1.0-2.2)$ & 19 & 68288 & 1.2 & $(0.7-2.0)$ \\
\hline Diuretic & 22 & 71157 & 1.7 & $(1.1-2.6)$ & 70 & 227812 & 1.7 & $(1.3-2.2)$ & 46 & $19050 \mid$ & 1.4 & $(1.0-1.9)$ \\
\hline Thiazides & 7 & 40613 & 0.9 & $(0.4-1.9)$ & 36 & $|2076|$ & 1.5 & $(1.1-2.2)$ & 19 & 87516 & I. & $(0.7-1.8)$ \\
\hline $\begin{array}{l}\text { Sulphonamides and } \\
\text { other low-ceiling diuretics }\end{array}$ & I & 4257 & 1.3 & $(0.2-9.2)$ & 3 & 15006 & 1.1 & $(0.3-3.4)$ & 5 & 16144 & 1.7 & $(0.7-4.1)$ \\
\hline $\begin{array}{l}\text { Loop (high-ceiling) } \\
\text { diuretics }\end{array}$ & 17 & 30512 & 2.5 & $(1.5-4.1)$ & 37 & 84227 & 2.1 & $(1.5-3.0)$ & 16 & 53572 & 1.6 & $(0.9-2.7)$ \\
\hline Potassium-sparing agents & 9 & 6338 & 6.0 & $(3.1-\mid 1.8)$ & 5 & 14607 & 1.5 & $(0.6-3.7)$ & । & 9606 & 0.5 & $(0.1-3.6)$ \\
\hline $\begin{array}{l}\text { Diuretics and potassium- } \\
\text { sparing agents in } \\
\text { combination }\end{array}$ & 5 & 13457 & 2.1 & $(0.9-5.1)$ & 12 & 48587 & 1.4 & $(0.8-2.5)$ & 8 & 49393 & 0.9 & $(0.4-1.8)$ \\
\hline
\end{tabular}

${ }^{a}$ All analyses adjusted for age, gender and calendar period. 
Table 4 Relative rates (RR) and 95\% confidence intervals (Cl) for the relation between antihypertensive medication use and renal cell cancer (RCC) by number of prescriptions in North Jutland County, 1989-2002

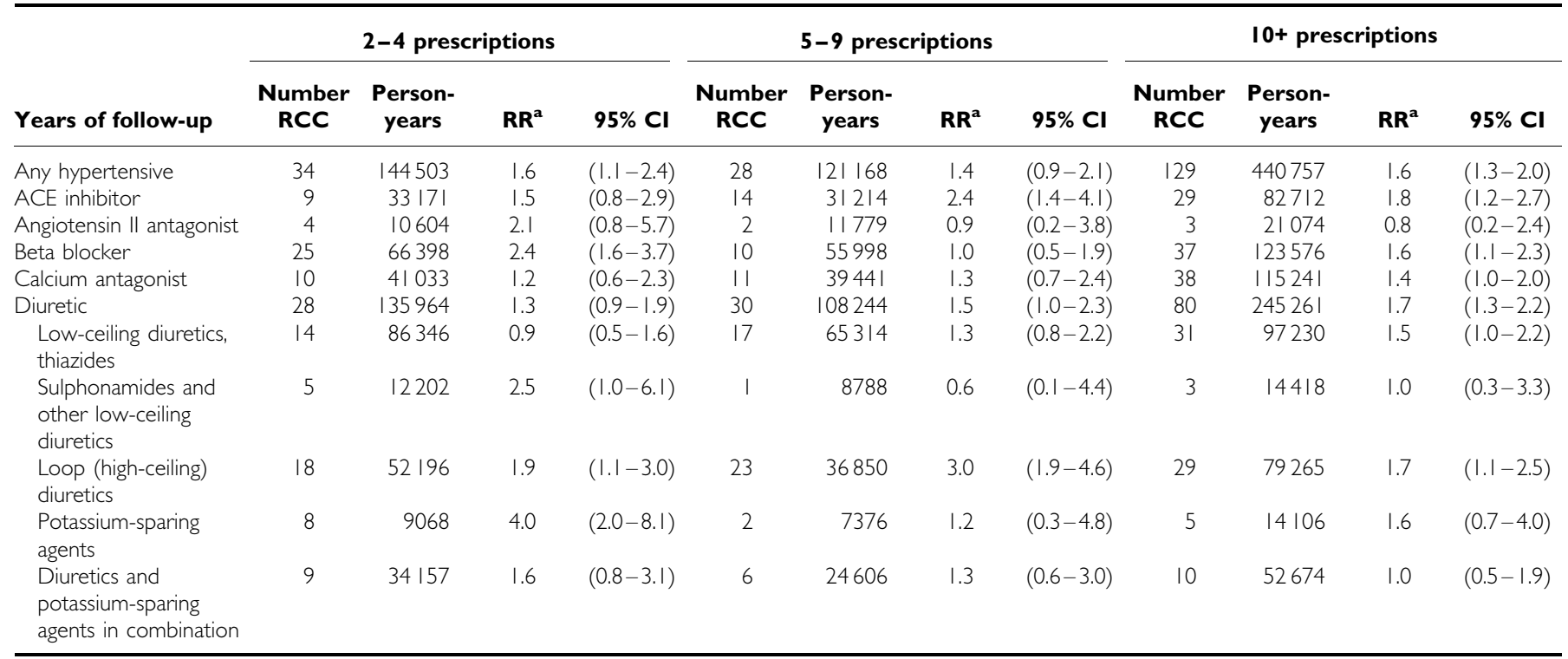

${ }^{a}$ All analyses adjusted for age, gender and calendar period.

AHT use and RCC decreased over time $(\mathrm{RR}$ for $<1$ year $=2.0,95 \%$ $\mathrm{CI}=1.4-2.9 ; \mathrm{RR}$ for $1-4$ years $=1.6,95 \% \mathrm{CI}=1.2-2.0$; $\mathrm{RR}$ for 5 and more years $=1.4,95 \% \mathrm{CI}=1.0-1.8$ ). A similar pattern of decreasing risk with increasing duration of follow-up was found for ACE inhibitors, angiotensin II antagonist, beta blockers and calcium antagonists. Overall, for the various classes of diuretics, no trends of increasing or decreasing risks were apparent over time. None of the specific types of AHT drugs was significantly associated with RCC after 5 or more years of follow-up.

Overall, no increasing or decreasing trend in RCC risk with increasing number of prescriptions for AHT medications was apparent (Table 4). Similar patterns were seen for the specific classes of AHT and diuretics in particular. RRs were remarkably similar for individuals with 10 or more prescriptions for virtually all classes of AHT medications with point estimates ranging between 1.4 and 1.8, and for the various types of diuretics, with point estimates ranging from 1.0 to 1.7 .

\section{DISCUSSION}

Although, there was an increased risk for RCC among users of AHT medications compared with nonusers in the general population, risk for exclusive use of any class of AHT medication was not significantly elevated compared with either the general population or with users of beta blockers. In fact, in comparison with beta blockers, the risk estimates were close to unity for all major groups of AHT medications. Neither duration of follow-up nor number of prescriptions was associated with RCC for any of the classes of AHT medications.

It is known that early-stage prediagnostic renal tumours may themselves lead to increases in blood pressure and the observed association between AHT medication and RCC is likely to reflect to some extent this type of protopathic bias. Our data lend some support for this view. After 5-years of follow-up, the risk ratios for all classes of AHT medications decreased, indicating that the onset of hypertension as an early sign of kidney cancers rather than the treatment per se is related to RCC.

Numerous observational studies have suggested that elevated risk ratios, may, in fact, reflect a relation between pre-existing high blood pressure and RCC. Thus, failure to adjust for confounding by pre-existing hypertension in our study may have generated inflated risk estimates. When adjustment for high blood pressure is performed, it appears to eliminate the excess risk associated with diuretic use (McLaughlin et al, 1995). We examined the specific classes of diuretics and found similar risks across all groups. As the five classes of diuretics have different modes of action, it is reasonable to assume that if these medications were related to RCC, risk would differ across the specific classes of diuretics. This was not the case in our study, as the risk for RCC was similarly elevated for all classes of diuretics. When compared with beta blockers, the risk for RCC among each group of diuretics except potassium-sparing agents was near unity and no trend in risk was apparent with increasing duration of follow-up or number of prescriptions. Only one case of RCC was diagnosed among users of potassium-sparing agents. Based on past studies in this population and others, it is unlikely that calcium antagonists or beta blockers, or ACE inhibitors are associated with cancer (McLaughlin et al, 1995; Olsen et al, 1997; McLaughlin and Lipworth, 2000; Sorensen et al, 2000; Friis et al, 2001; Grossman et al, 2001). To our knowledge this is the first study to examine the relation between angiotensin II antagonists and RCC.

The strengths of the study include the large size with over 3 million person-years of follow up and 471 cases of RCC resulting in an improved statistical precision compared with earlier studies, and complete follow-up of the cohort through use of the unique CPR number with computerised linkage to nationwide Danish registers. A further strength is that beta-blockers are available in Denmark only by prescription, and we have identified practically all users in the study population. The limitations include the fact that the prescription database was only established in 1989 so earlier drug history is unknown. Information on well known or suspected risk factors for RCC, such as cigarette smoking, obesity and possibly hypertension was not available. Several large-scale population-based case-control and cohort studies which adjusted for use of diuretics and other AHT have reported elevated relative risks for RCC associated with hypertension, independent of use of AHT (McLaughlin et al, 1995; Yuan et al, 1998; Chow et al, 2000; McLaughlin and Lipworth, 2000). In contrast, adjustment for high blood pressure appears to eliminate any excess risk for RCC 
associated with AHT use (McLaughlin et al, 1995; Yuan et al, 1998; Shapiro et al, 1999; McLaughlin and Lipworth, 2000). In an attempt to control for potential confounding variables, we compared beta blockers and other medications and found that all of the risk estimates were close to expectation.

Diabetes has been suggested as a risk factor for RCC, but the evidence is not consistent (Wideroff et al, 1997; Coughlin et al, 2004). Exclusion of diabetics did not materially change the risk estimates (data not shown), suggesting that diabetes does not play a major role in the aetiology of RCC in this cohort.

In summary, none of the AHTs studied was consistently associated with risk of RCC, and analyses by duration of followup and number of prescriptions indicated that it is unlikely that any of these medications plays an important role in the aetiology of RCC. Elevated RRs for RCC among of AHT users compared with the general population are unlikely to be causal, but rather reflect confounding, from failure to control for pre-existing hypertension, which appears to be an independent risk factor for RCC, from hypertension as an early sign of kidney cancer and possibly from increased medical surveillance.

\section{ACKNOWLEDGEMENTS}

This study was funded by the International Epidemiology Institute, Rockville, Maryland, USA, the Ingeborg and Leo Dannins Foundation for Scientific Research, and the Western Danish Research Forum for Health Sciences (Vestdansk Forskningsforum).

\section{REFERENCES}

Capella D (1993) Descriptive tools and analysis. In Drug Utilization Studies: Methods and Uses WHO Regional Publications, European Series No. 45, Dukes MNG (ed) pp 55-78. Geneva: World Health Organization

Chobanian AV, Bakris GL, Black HR, Cushman WC, Green LA, Izzo Jr JL, Jones DW, Materson BJ, Oparil S, Wright Jr JT, Roccella EJ, National Heart, Lung, and Blood Institute Joint National Committee on Prevention, Detection, Evaluation, and Treatment of High Blood Pressure; National High Blood Pressure Education Program Coordinating Committee (2003) The seventh report of the Joint National Committee on Prevention, Detection, Evaluation, and Treatment of High Blood Pressure: the JNC 7 Report. JAMA 289(19): 2560-2572

Chow WH, Gridley G, Fraumeni Jr JR, Jarvholm B (2000) Obesity, hypertension and the risk of kidney cancer in men. $N$ Engl J Med 343: $1305-1311$

Coughlin SS, Calle EE, Teras LR, Petrelli J, Thun MJ (2004) Diabetes mellitus as a predictor of cancer mortality in a large cohort of US adults. Am J Epidemiol 159: 1160 - 1167

Friis S, Sorensen HT, Mellemkjaer L, McLaughlin JK, Nielsen GL, Blot WJ, Olsen JH (2001) Angiotensin-converting enzyme inhibitors and the risk of cancer: a population-based cohort study in Denmark. Cancer 92: 2462-2470

Grossman E, Messerli FH, Goldbourt U (2001) Antihypertensive therapy and the risk of malignancies. Eur Heart J 22: 1343 - 1352

McLaughlin JK, Chow WH, Mandel JS, Mellemgaard A, McCredie M, Lindblad P, Schlehofer B, Pommer W, Niwa S, Adami HO (1995) International renal-cell cancer study. VIII. Role of diuretics, other antihypertensive medications and hypertension. Int J Cancer 63: 216-221

McLaughlin JK, Lipworth L (2000) Epidemiologic aspects of renal cell cancer. Semin Oncol 27: 115-123

Mellemgaard A, Carstensen B, Norgaard N, Knudsen JB, Olsen JH (1993) Trends in the incidence of cancer of the kidney, pelvis, ureter and bladder in Denmark 1943-88. Scand J Urol Nephrol 27: 327-332

Olsen JH, Sorensen HT, Friis S, McLaughlin JK, Steffensen FH, Nielsen GL, Andersen M, Fraumeni Jr JF, Olsen J (1997) Cancer risk in users of calcium channel blockers. Hypertension 29: $1091-1094$

Shapiro JA, Williams MA, Weiss NS, Stergachis A, LaCroix AZ, Barlow WE (1999) Hypertension, antihypertensive medication use, and risk of renal cell carcinoma. Am J Epidemiol 149: 521-530

Sorensen HT, Olsen JH, Mellemkjaer L, Marie A, Steffensen FH, McLaughlin JK, Baron JA (2000) Cancer risk and mortality in users of calcium channel blockers. A cohort study. Cancer 89: 165-170

The WHO Collaborating Centre for Drug Statistics Methodology [Internet] (2004). Oslo, Norway: Norwegian Institute of Public Health, [updated $2004 \mathrm{Jan}$ 5; cited $2004 \mathrm{Jul}$ 27]. Available from: http://www.whocc.no/ atcddd/

The World Health Report (2002) Reducing Risks Promoting Health Life. Geneva, Switzerland: World Health Organization, p 58

Wideroff L, Gridley G, Mellemkjaer L, Chow WH, Linet M, Keehn S, BorchJohnsen K, Olsen JH (1997) Cancer incidence in a population-based cohort of patients hospitalized with diabetes mellitus in Denmark. J Natl Cancer Inst 89: $1360-1365$

Yu MC, Mack TM, Hanisch R, Cicioni C, Henderson BE (1986) Cigarette smoking, obesity, diuretic use, and coffee consumption as risk factors for renal cell carcinoma. J Natl Cancer Inst 77: 351-356

Yuan JM, Castelao JE, Gago-Dominguez M, Ross RK, Yu MC (1998) Hypertension, obesity and their medications in relation to renal cell carcinoma. Br J Cancer 77: 1508-1513 